\title{
Particle measurement technology based on RDE testing differentiation studies
}

\author{
Yuanjun Zhang ${ }^{1}$, Yuebing Li ${ }^{1}$, Honglei Dong ${ }^{2, *}$, Chao Dong ${ }^{1}$, and Hongquan Pan $^{1}$ \\ ${ }^{1}$ Xiang Yang DA'AN Automobile Testing Center Limited, China \\ ${ }^{2}$ China National Institute of Standardization, China
}

\begin{abstract}
Keywords: emission, particle, DC, CPC.
Abstract. In the vehicle emission test, there are many kinds of measurement equipment for particulate matter, and their measurement principles are also different. By using two kinds of equipment with different principle of particle measurement, the difference of measurement results under the same conditions is compared and the reasons are analyzed. The results show that more particles with particle size less than $50 \mathrm{~nm}$ are measured by DC principle, and the concentration of particles with small particle size is higher, so that the $\mathrm{PN}$ measurement results using DC principle test are higher than those using CPC principle test results. The measurement results of the CPC and DC principle test equipment during the transient process are very similar, but DC is more sensitive to small-particle particle testing and can test small-particle particles up to $10 \mathrm{~nm}$, so the test concentration is higher than that of CPC.
\end{abstract}

\section{Summary}

As the number of internal combustion engine vehicles in our country increases year by year, the corresponding exhaust emissions (mainly including $\mathrm{HC}, \mathrm{CO}, \mathrm{NOx}, \mathrm{PM}$ ) have also become an issue of increasing concern. In 2017, motor vehicle particulate matter (PM) emissions reached 509,000 tons, of which 488,000 tons were emitted by automobiles, accounting for $95.8 \%$, and low-speed automobiles emitted 21,000 tons, accounting for $4.2 \%$ $[1]$.

With the development of technology, gasoline direct injection (GDI) gasoline engines are widely used in gasoline engines due to their good fuel economy and advantages in reducing $\mathrm{CO} 2$ emissions [2]. GDI gasoline engine can accurately control the fuel injection time and fuel injection volume, and has high fuel economy [3]. However, due to the use of in-cylinder injection, the mixing time of oil and gas is shortened, resulting in local uneven mixing, local fuel concentration, and even incomplete combustion, thereby increasing particulate matter emissions, and its emission level even exceeds that of diesel engines with DPF[4, 5]. In view of this, direct-injection gasoline engines are currently the main emission source of ultrafine particles. In addition to increasing the frequency of emission detection for their particulate emissions, high-efficiency filters will also be required to treat exhaust gas in the future [6].

\footnotetext{
* Corresponding author: donghl@dpac.gov.c
} 
Merkisz J et al. compared vehicle emissions under NEDC and RDE operating conditions for light vehicles [7]; Weiss M studied the emission of European light vehicle road particulate matter and analyzed the distribution of particulate matter of different sizes [8,9]. In December 2016, my country issued the "Limits and Measurement Methods of Pollutant Emissions from Light-Duty Vehicles (China Phase 6)" (GB18352.6-2016), in which the real road emission test (referred to as RDE) entered the type approval requirements for the first time. It is required to only monitor and report the results before July 1. 2023, and before July 1. 2020, in the room temperature test, the gasoline vehicle PN transition limit is $6.0 \times 1012 / \mathrm{km}$, and after July 1, 2020, the PN implementation is $6.0 \times 1011 / \mathrm{km}$ limit requirements [10].

In the China 6 emission standards, the technical requirements for PN testing are based on the principle of electrostatic counting (Diffusion Charge Counter, DC method) and methods based on the principle of particle counting (Condensation Particle Counter, CPC method) are both accepted. However, in actual verification, the counting efficiency under different particle sizes is also different due to the different particle testing principles, which leads to differences in test consistency in the two methods.

At present, the EU and China's requirements for PN particle size only monitor the part above $23 \mathrm{~nm}$, and do not consider fine particles with a particle size less than $23 \mathrm{~nm}$. The latest EU research has begun to study ultrafine particles with a particle size less than $23 \mathrm{~nm}$. A lot of research has been done in the medical field. Ultrafine particles contain a lot of carcinogens, which are more likely to enter the human blood through the respiratory system, posing a huge threat to human health. Our country has also begun to consider limiting ultrafine particles with a particle size of less than $23 \mathrm{~nm}$.

In the RDE test equipment, the test equipment used to test the PN has both the CPC test principle and the DC test principle. Different testing principles have different particle size ranges for PN testing.

The particle size measured by the portable emission measurement system (PEMS) based on the DC principle and the PEMS based on the CPC principle are different, and the efficiency under different particle size distributions is also different. The counting efficiency of CPC reaches $50 \%$ at $23 \mathrm{~nm}$ and $90 \%$ at $41 \mathrm{~nm}$, that the cutting particle size is $23 \mathrm{~nm}$ [8]. The minimum particle size of PEMS based on the DC principle can be measured to $10 \mathrm{~nm}$, and in the particle size distribution of vehicle pollutant emissions, the smaller the particle size, the greater the number of particles $[11,12]$. Therefore, the difference in the size of the measured particles is the main reason for the difference in the comparison between the two.

We compare the PN test equipment with the DC test principle and the CVS with the CPC test principle to study the difference between $\mathrm{PN}$ test equipment with different test principles. And study its relevance.

\section{Test equipment and methods}

\subsection{Test vehicle}

The test vehicle is a China 6 light vehicle, and its basic parameters are shown in Table 1:

Table 1. Basic parameters of the test vehicle.

\begin{tabular}{cc}
\hline \multicolumn{1}{c}{ Vehicle Parameter } \\
curb weight & $1360 \mathrm{~kg}$ \\
Fuel Type & China 6 \\
Emission standard & China 6 \\
Maximum net power of engine & $126 \mathrm{~kW}$ \\
\hline Engine displacement & $1.6 \mathrm{~L}$ \\
\hline Fuel injection mode & Direct injection \\
\hline
\end{tabular}




\subsection{Test equipment}

In the CVS test system of domestic testing centers and major automakers' laboratories, the PN test principle is mainly based on the CPC test principle, of which the SCPS2000 of Japan HORIBA is the majority. Therefore, based on the test results of the Continuous Constant Volume Sampling (CVS) system, the CPC test principle data is also recognized as comparable test data.

In the vehicle mounted equipment, the PN test equipment adopts the CPC principle and the DC principle. The particle size tested by the two is different, and the efficiency under different particle size distributions is also different. The PEMS based on the DC principle can measure as small as 10 nanometers, and in the particle size distribution of pollutant emissions, the smaller the particle size, the greater the number of particles. The China 6 Standard specifies the allowable error requirements of vehicle equipment relative to the CVS system, as shown in Table 2.

Table 2. Relative CVS system test error of vehicle equipment.

\begin{tabular}{|c|c|}
\hline Parameters & allowable error \\
\hline $\mathrm{NMHC}^{(1)}(\mathrm{mg} / \mathrm{km})$ & $\begin{array}{c} \pm 20 \mathrm{mg} / \mathrm{kmOr} 20 \% \text { of the laboratory reference value, whichever is } \\
\text { greater }\end{array}$ \\
\hline $\mathrm{PN}^{(2)}($ 个/km) & $\begin{array}{c} \pm 1 \times 10^{11} \text { 个 } / \mathrm{kmOr} 50 \% \text { of the laboratory reference value, whichever } \\
\text { is greater }\end{array}$ \\
\hline $\mathrm{CO} /(\mathrm{mg} / \mathrm{km})$ & $\begin{array}{c} \pm 1 \times 150 \mathrm{mg} / \mathrm{kmOr} 15 \% \text { of the laboratory reference value, whichever } \\
\text { is greater }\end{array}$ \\
\hline $\mathrm{CO}_{2} /(\mathrm{mg} / \mathrm{km})$ & $\begin{array}{c} \pm 10 \mathrm{~g} / \mathrm{kmOr} 10 \% \text { of the laboratory reference value, whichever is } \\
\text { greater }\end{array}$ \\
\hline $\mathrm{NO}_{x} /(\mathrm{mg} / \mathrm{km})$ & $\begin{array}{c} \pm 15 \mathrm{mg} / \mathrm{kmOr} 15 \% \text { of the laboratory reference value, whichever is } \\
\text { greater }\end{array}$ \\
\hline
\end{tabular}

(1) It is only applicable when the vehicle speed is obtained from the ECU; in order to meet the error requirements, it is allowed to adjust the ECU's speed measurement based on the verification results..

(2) Only required if PN test is carried out.

\subsubsection{CPC test principle}

In the world of nanoparticles, where the size of particles is less than $100 \mathrm{~nm}$, it is impossible to be classified by weight. In this field, particles are classified and counted according to size, and the special physical properties of particles are used to complete the analysis of quantity concentration.

The condensed particle counter (CPC) uses the characteristics of gas condensation on the surface of solid particles to count. The airflow containing particles passes through the heated liquid saturated evaporation module (1), and then generates a supersaturated environment (2).

With subsequent cooling in the condensation module, the liquid condenses on the particles contained in the airflow. (4) The droplets (5) produced can be measured using the optical sensor (6). Depending on the application, for example, benzene, isopropanol or water can be used as the working fluid (3). After the measurement is completed, the condensed particles are separated from the sample gas, that is, the air, and then discharged (8), as shown in Figure 1. 


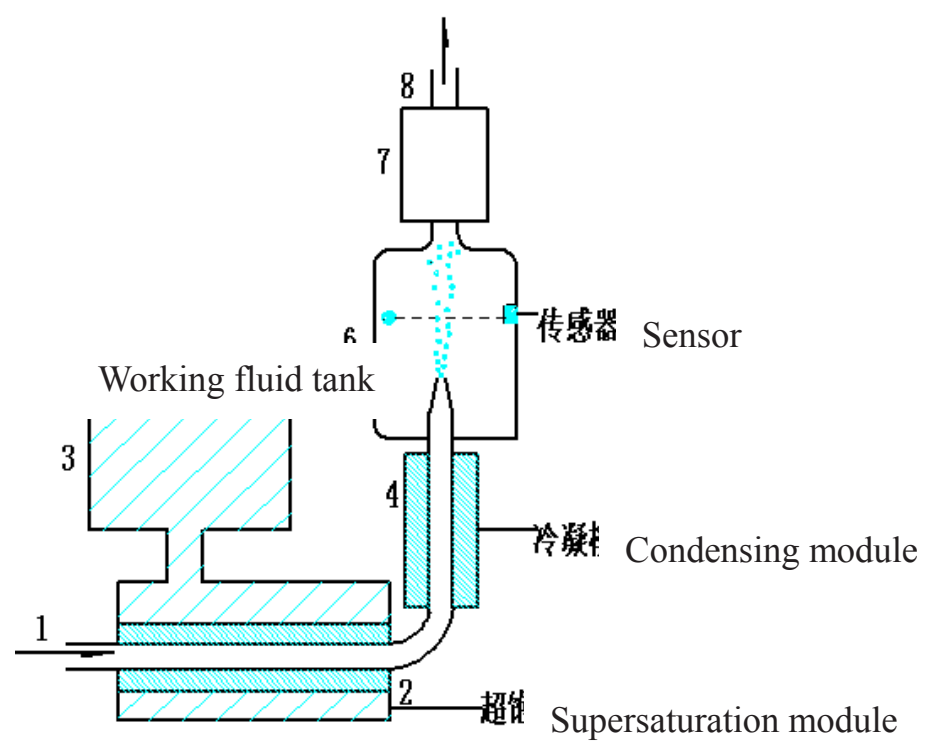

Fig. 1. Test principle of the condensation particle counter (CPC).

Optical sensors usually use the principle of light scattering. This means that the sample gas needs to pass through the beam, and the particles in it make the beam have a scattering effect. The scattering effect is detected by the photoelectric sensor, and through signal analysis, the particle number concentration information can be obtained. Laser scattering is usually only applicable to particles larger than nanometers. This principle limitation can be solved by increasing the particle diameter through the coagulation module.

\subsubsection{DC test principle}

No matter how small the particles are, they can be charged, transported and released. The principle of measuring the number of diffusively charged particles is that technology uses this characteristic of particles. The DC sensor uses this principle. This sensor contains a charging chamber, in which an alternating electric field can power the particles, and the power can be detected in the subsequent single-pole or multi-level sensors. The instrument using this principle does not require any auxiliary working materials, nor any radioactive source to neutralize the charge of the particles to be measured. This sensor structure is very suitable for mobile applications.

The charge diffusion method uses particles as a charge transport medium. The principle of Brownian motion determines that the movement of small particles is the strongest, and they tend to deposit on the corresponding filter. The large particles are relatively more inert due to the relatively strong charge, so it is easy to follow the airflow and pass through the filter prepared for this application. The smaller particles separated by the first-stage filter release charges on the conductive filter, and the number of particles can be inversely calculated by measuring the current generated. The larger particles in the sample are deposited on the downstream filter-also called the zero point filter and the current generated is also measured. 


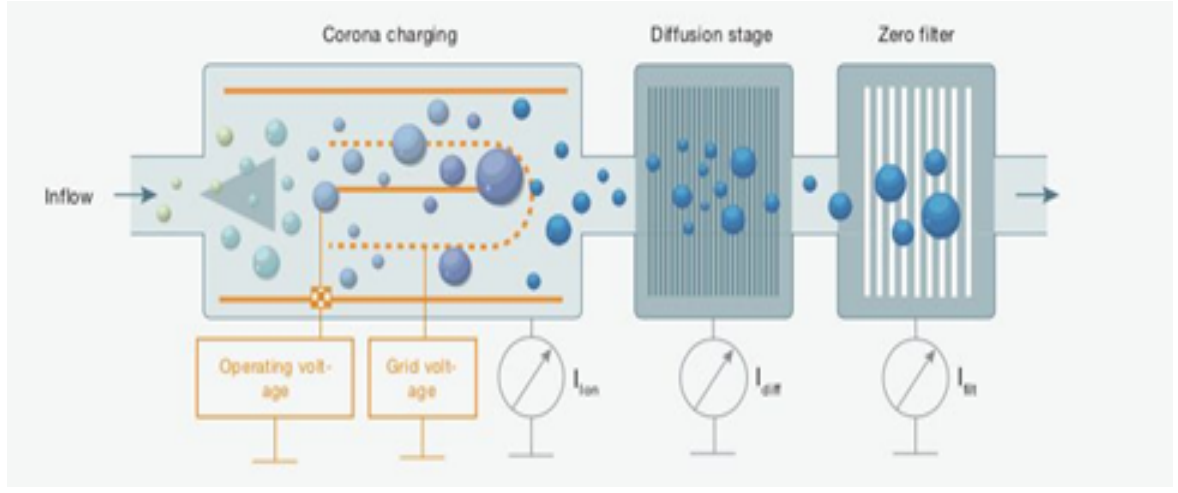

Fig. 2. Electrostatic counter (DC) testing principle.

The difference between the two sensor charges can be used to calculate the modal value of the particle. The modal value can be used to indicate the particle size with the largest particle number concentration. In a single-modal distribution curve, the modal value is the highest point of the particle concentration on the curve.

\section{Test data and analysis}

\subsection{Gravimetric analysis of particulate matter}

Use Testo NM3 (DC test principle) instrument and HORIBA PMP SCPS2000 (CPC principle) sampling equipment to measure particulate matter (only PN test is considered). The results of the measurement under three different conditions are shown in Table 3.

Table 3 Comparison of NM3 and CVS under different conditions

the table 3 shows when the dilution ratio $\mathrm{DF}=300$, the difference in the NM3/CVS ratio of the particulate matter between the first time and the second time of different equipment is the smallest; under the second measurement of different dilution ratios, as the dilution ratio increases, CVS and NM3 Both measurements increase by an order of magnitude.

From Figure 3, we can see the consistency of the CVS and NM3 dynamic measurement signals. Even if the particle concentration is of low order of magnitude, NM3 can reproduce the dynamics of the measurement very well. Compared with CVS, the measured transient period and static period are very similar in the NM3 signal process; the DC measurement principle provides faster than CPC Response time. This is an important feature of exhaust gas measurement, especially for transient measurements. The peak concentration detected by NM3 is higher than that of CPC.

The first measurement: (dilution factor $(\mathrm{DF})=300)$

\begin{tabular}{ccc}
\hline & Pt/Test Per Second & Pt \\
\hline NM3 & See Figure 5(a) & $1.88117 \mathrm{E}+12$ \\
CVS & See Figure 5(a) & $4.35724 \mathrm{E}+11$ \\
& 比值(NM3/CVS) & 4.31 \\
\hline \multicolumn{3}{c}{ The second measurement: (dilution factor (DF) $=150)$} \\
NM3 & Pt/每秒测试 & Pt \\
CVS & See Figure 5(b) & $2.1768 \mathrm{E}+12$ \\
\hline
\end{tabular}




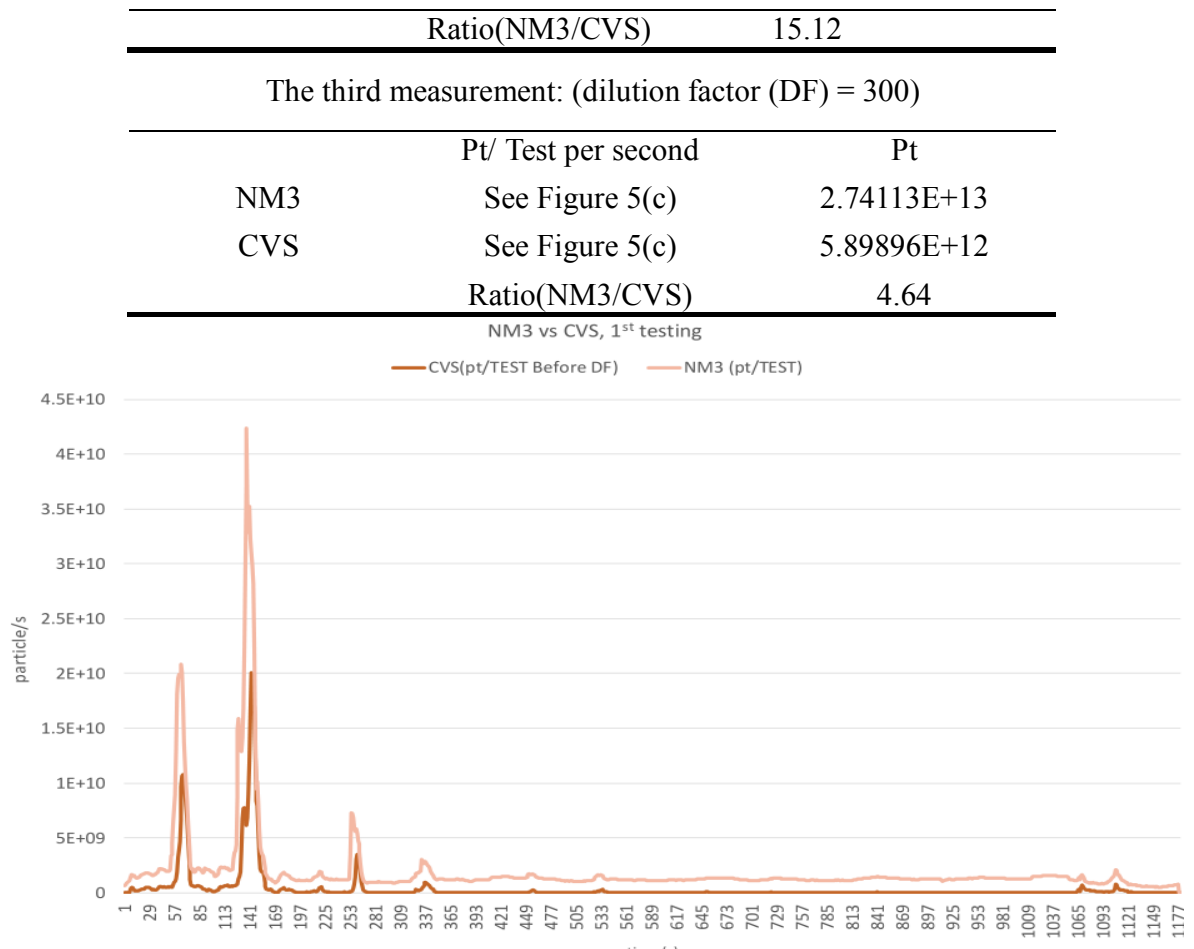

(a)

NM3 vs CVS, $2^{\text {nd }}$ testing

- CVS(pt/TEST Before DF) - NM3 (pt/TEST)

$1.2 \mathrm{E}+11$

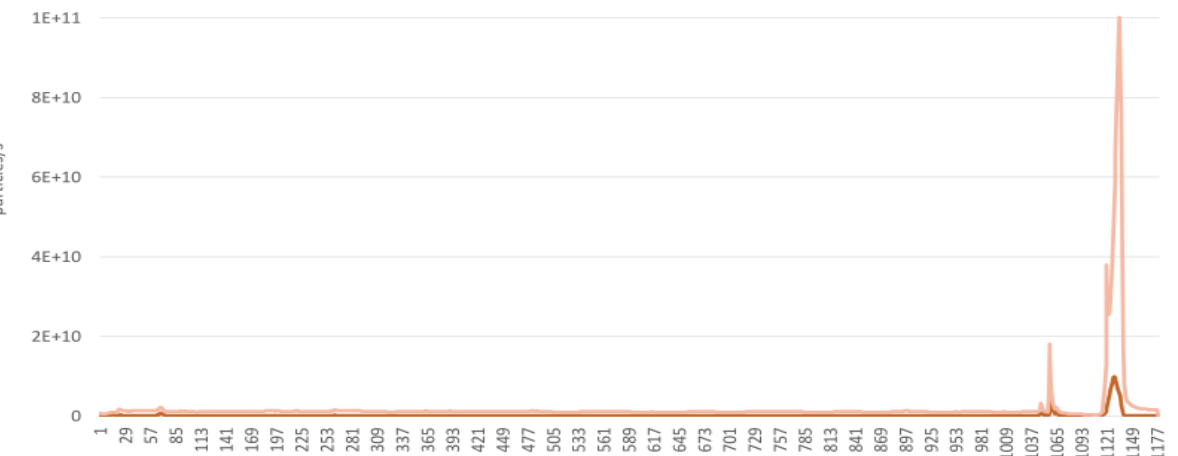

(B) 


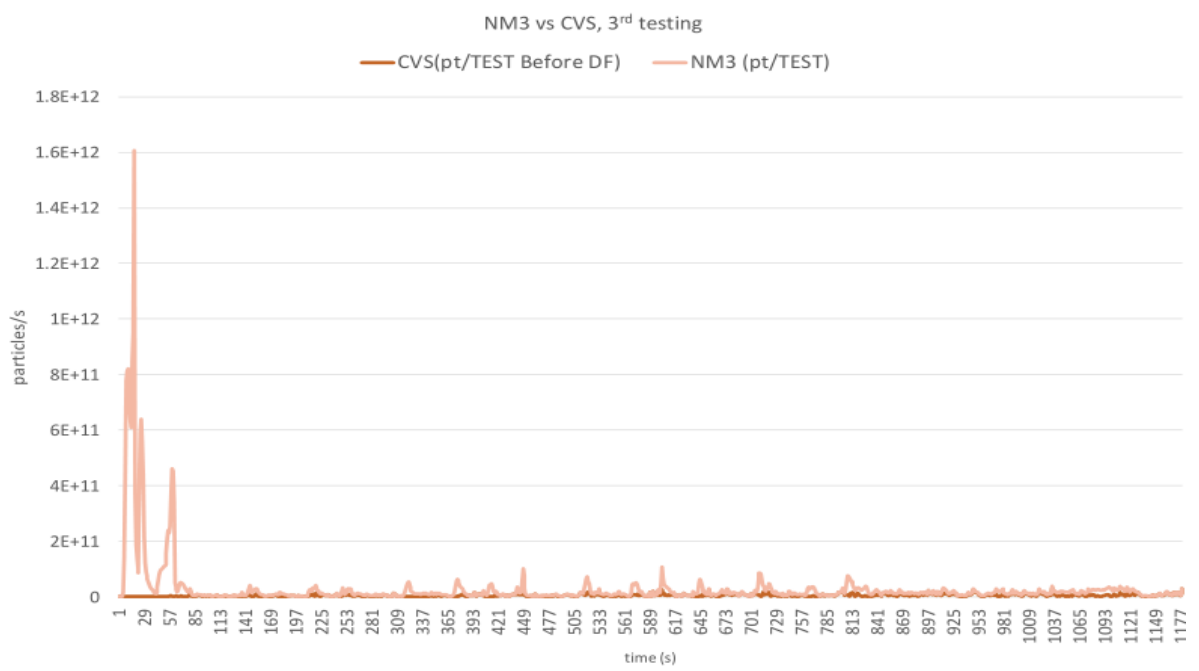

(C)

Fig. 3. Comparison of Modal Data Between DC Test and CVS Test.

\subsection{Particle concentration level analysis}

It can be seen from the comparison of 3 that the magnitude of the measured particle concentration is very low. The concentration of surrounding air particles is expected to be about $1.0 \mathrm{E}+4 \mathrm{pt} / \mathrm{ccm}$. The average particle concentration of all tests carried out is shown in Table 4:

Table 4. The average concentration of particles in three comparison tests.

\begin{tabular}{llll}
\hline $\begin{array}{l}\text { Average particle } \\
\text { concentration }\end{array}$ & \multicolumn{1}{c}{ First test } & Second test & The third test \\
\hline NM3 & $1.6 \mathrm{E}+9 \mathrm{pt} / \mathrm{s}$ & $1.8 \mathrm{E}+9 \mathrm{pt} / \mathrm{s}$ & $4.6 \mathrm{E}+10 \mathrm{pt} / \mathrm{s}$ \\
& $7.1 \mathrm{E}+3 \mathrm{pt} / \mathrm{ccm}$ & $8.1 \mathrm{E}+3 \mathrm{pt} / \mathrm{ccm}$ & $1 \mathrm{E}+5 \mathrm{pt} / \mathrm{ccm}$ \\
& $3.7 \mathrm{E}+8 \mathrm{pt} / \mathrm{s}$ & $1.2 \mathrm{E}+8 \mathrm{pt} / \mathrm{s}$ & $1.0 \mathrm{E}+10 \mathrm{pt} / \mathrm{s}$ \\
$\mathrm{CVS}$ & $1.6 \mathrm{E}+3 \mathrm{pt} / \mathrm{ccm}$ & $5.4 \mathrm{E}+2 \mathrm{pt} / \mathrm{ccm}$ & $2.2 \mathrm{E}+4 \mathrm{pt} / \mathrm{ccm}$
\end{tabular}

Only the third test showed that the average particle concentration was higher than the ambient air concentration. When NM3 uses 1:10 dilution factor (DF) to detect, its measurement accuracy is $1.0 \mathrm{E}+4 \mathrm{pt} / \mathrm{ccm}$, which is currently expected ambient air particle concentration. In other words, when the measured concentration is lower than $1.0 \mathrm{E}+4 \mathrm{pt} / \mathrm{ccm}$, they are all within the noise range of NM3. Therefore, measurements below $1.0 \mathrm{E}+4 \mathrm{pt} / \mathrm{ccm}$ should be unreliable.

However, there is a good correlation between DC and CVS systems. As shown in the figure, there is a strong correlation with particle concentration greater than $1.0 \mathrm{E}+8 \mathrm{pt} / \mathrm{s}$.

\subsection{Analysis of the number of particles}


There are smaller particles in the vehicle exhaust gas measured three times, which is the reason for the higher concentration measured by nanometer. These small particles can form nodules during the measurement process, and because of their lower cut-off point, they are easily detected by DC, but CPC cannot. The cut-off point is described as the average particle diameter, and the particle counter performs at $50 \%$ efficiency. The efficiency of DC is shown in the figure below

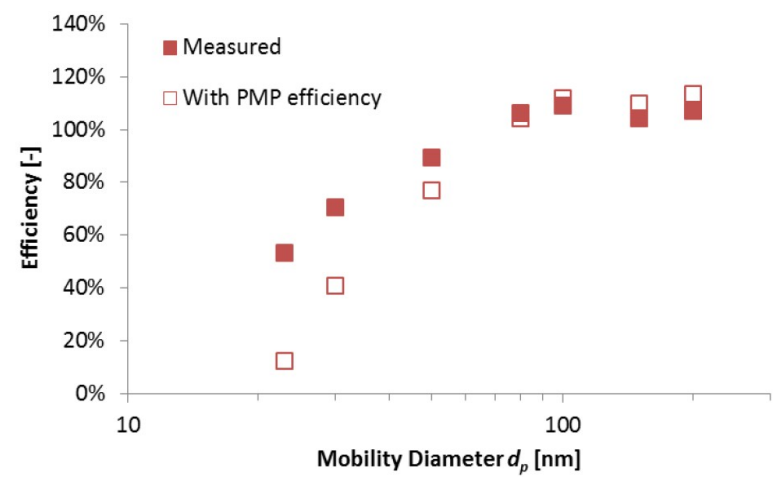

Fig. 5. Comparison of DC and CPC Test Efficiency.

For DC, the detection rate below $23 \mathrm{~nm}$ is less than $50 \%$, the detection rate above $50 \mathrm{~nm}$ is greater than $70 \%$, and for larger sizes. In other words, DC can measure smaller particles, but CPC does not detect them. Using the particle size data provided by DC, it can be determined that there are small particles during the measurement. Figure 6 shows the particle concentration of DC and CPC in all 3 experiments.

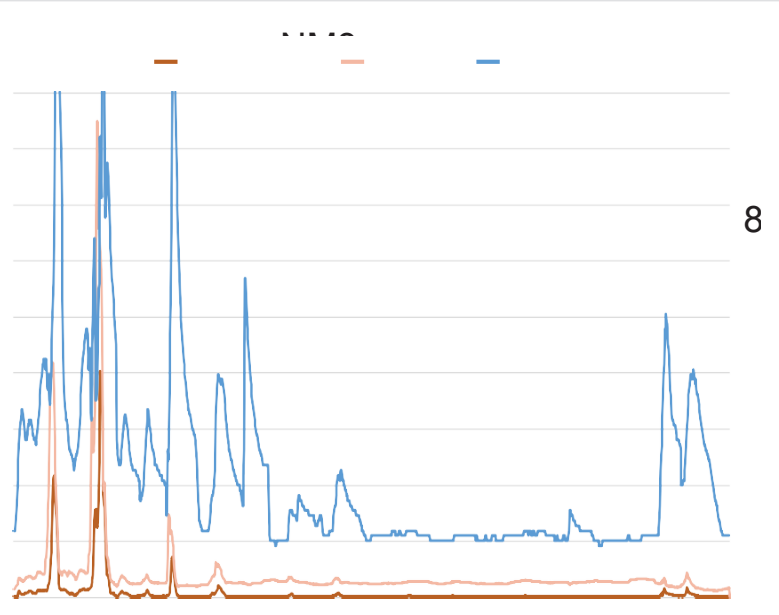

Fig. 6. The Particle Concentration and Size of NM3 and CVS in the First Measurement.

The particle size of diesel combustion engine is $80-100 \mathrm{~nm}$, and the particle size of gasoline direct injection (GDI) is about $60-70 \mathrm{~nm}$. Figure 7 shows that the particle diameter at almost all concentration peaks is less than $70 \mathrm{~nm}$, and the diameter at rest concentration is less than $20 \mathrm{~nm}$. 


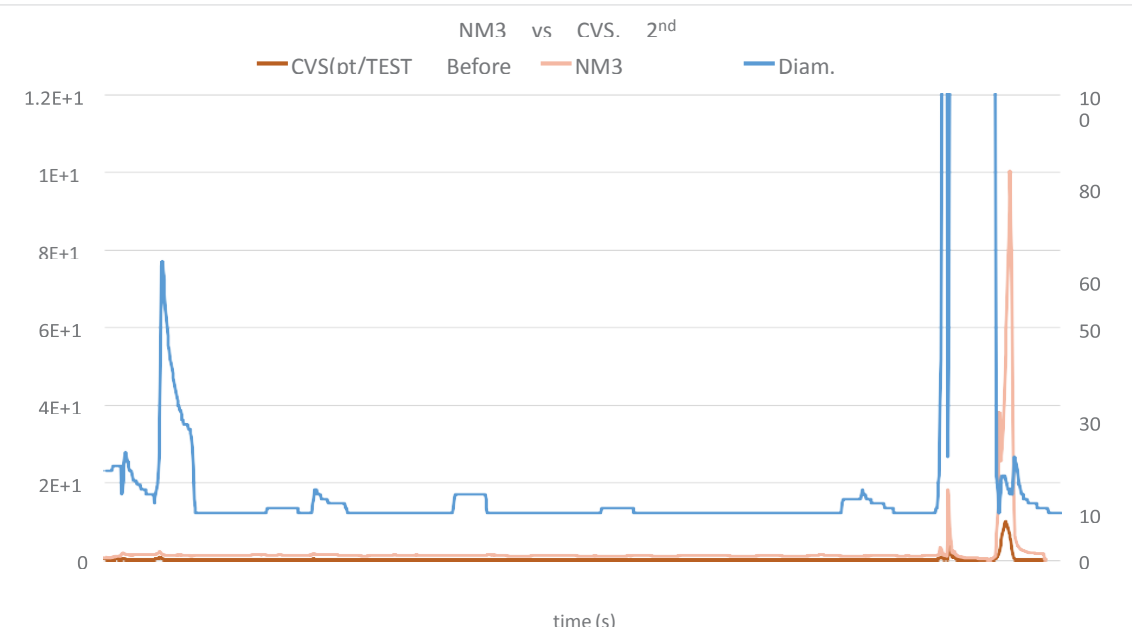

Fig. 7. The Particle Concentration and Size of NM3 and CVS in the Second Measurement.

The figure 8 shows bigger particle diameters than the tests 1 and 2 but again under $70 \mathrm{~nm}$ during a long period of the measurement.

This is because DC has a lower cut-off point than CVS. Although in principle, DC can be adjusted to $23 \mathrm{~nm}$ like CPC. However, the actual road emission (RDE) test procedures have not yet determined the efficiency below $23 \mathrm{~nm}$. The following table shows the efficiency of RDE's PEMS-PN window.

Although in principle, DC can be adjusted to $23 \mathrm{~nm}$ like CPC. However, the actual road emission (RDE) test procedures have not yet determined the efficiency below $23 \mathrm{~nm}$. The table 5 shows the efficiency of RDE's PEMS-PN window.

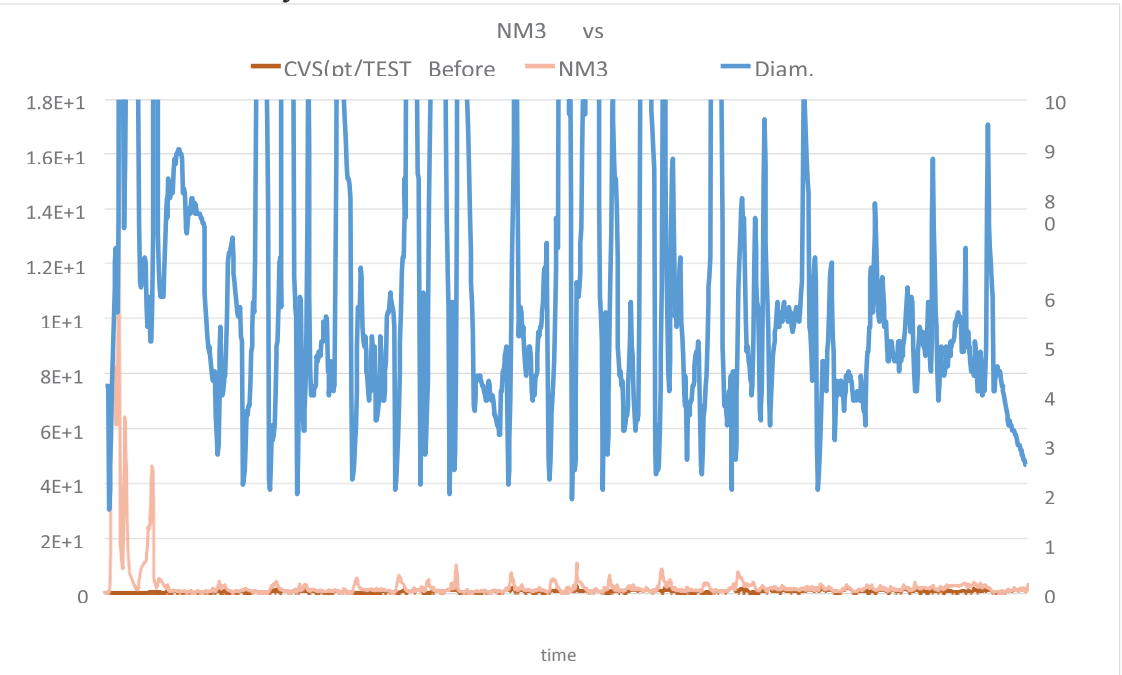

Fig. 8. Particle Size Distribution in Transient Test.

Table 5. PEMS-PN window efficiency.

\begin{tabular}{cccccccc}
\hline$d_{p}(\mathrm{~nm})$ & $<23$ & 23 & 30 & 50 & 70 & 100 & 200 \\
\hline effectiveness & $\begin{array}{c}\text { To be } \\
\text { confirmed }\end{array}$ & $0.2-0.6$ & $0.3-1.2$ & $0.6-1.3$ & $0.7-1.3$ & $0.7-1.3$ & $0.5-2.0$ \\
\hline
\end{tabular}




\section{Conclusion}

1) Generally speaking, the particle concentration tested is very low $(<10,000 \mathrm{pt} / \mathrm{cm})$. The concentration of surrounding air particles is expected to be about $1.0 \mathrm{E}+4 \mathrm{pt} / \mathrm{ccm}$.

2) Use 1:10 dilution factor (DF) detection, and the specified limit of DC test is $1.0 \mathrm{E}+4 \mathrm{pt} / \mathrm{ccm}$. For this reason, we can expect that even if the concentration is lower than $10,000 \mathrm{pt} / \mathrm{ccm}$, the DC principle can detect the PN value. The experimental measurement results show that compared with $\mathrm{CPC}$, the DC test data has a higher trend consistency. Even if the particle concentration is of low order of magnitude, DC can reproduce the dynamics of the measurement well.

3) The measurement results of the DC signal process are very similar to the CPC ratio, and the concentration of the DC test results is higher than that of the CPC. The possible reasons for the deviation of particle concentration are as follows: the response time of the diffuser to the CPC is faster, and the end points are different at the same time. The maximum, diffusion charging (DC) measurement principle provides a conversion response time than CPC. In the displacement of the transient period, the diffusion charge signal of DC shows a higher concentration trend than that of CPC. Taking into account that the total concentration of the three experiments is very low, the peak penetration difference has a significant deviation from the average concentration during the entire cycle. The possible reason for the higher concentration of the volume, DC measurement can be from the small particles present in the measured vehicle exhaust gas. These small particles may nucleate during the measurement. The particle size of diesel engines is expected to be $80-100 \mathrm{~nm}$, and the size distribution of gasoline direct injection (GDI). It is about $60-70 \mathrm{~nm}$. During the resting concentration period, the measurement of DC showed that the size during almost all concentration peaks and diameters $<20 \mathrm{~nm}$ was less than $70 \mathrm{~nm}$. Due to the cut-off point of $\mathrm{NM} 3$, the measurement efficiency of these particles is higher than that of CPC, so the DC concentration is higher than that of CPC.

The next step of the emission regulations is to further lower the PN limit to $10 \mathrm{~nm}$. It is necessary to consider the correlation between DC and CPC. It is necessary to consider the research and definition of the test efficiency of DC principle of small particle size (less than $50 \mathrm{~nm}$ ), so as to achieve the consistency and correlation of the two tests data.

\section{References}

1. Ministry of environmental protection. Annual report on environmental management of motor vehicles in China [R]. Beijing: Ministry of ecology and environment of the people's Republic of China, 2018

2. Wang Jiangxin, Wang Zhi. Research Progress of High Efficient and Clean Combustion of Automotive Gasoline Engines [J]. Journal of Automotive Safety and Energy, 2010, 1(3): 167-178.

3. Sun Yong, Wang Yanjun, Wang Jianxin, et al. New Progress of Gasoline Direct Injection Engines' Research and Technical Problems [J]. internal-combustion engine, 2002(1): 6-10.

4. Liang B, Ge Y S, Tan J W, et al. Comparison of PMemissions from a gasoline direct injected (GDI) vehicle and a port fuel injected (PFI) vehicle measured by electrical low pressure impactor (ELPI) with two fuels: Gasoline and M15 methanol gasoline[J]. Journal ofAerosol Science, 2013, 57: 22-31. 
5. Mathis U, Mohr M, Forss A M. Comprehensive particle characterization of modern gasoline and diesel passenger cars at low ambient temperatures[J] * Atmospheric Environment, 2005, 39(1): 107-117.

6. MERKISZ J, FUCP, LIJEWSKI P, etal. The comparison of the emissions from light duty vehicle in on-road and NEDC tests[C]. SAE Paper 2010-01-1298.

7. MERKISZ J, FUCP, LIJEWSKI P, etal. The comparison of the emissions from light duty vehicle in on-road and NEDC tests[C]. SAE Paper 2010-01-1298.

8. WEISS M, NNEL P, MMEL R, etal. On-road emissions of light-duty vehicles in Europe[J]. Environmental Science \& Technology, 2011,45( 19): 8575 -8581.

9. A spectrometer for measuring particle size distributions in the range of $3 \mathrm{~nm}$ to $10 \mu \mathrm{m}$. Liu J Q,Jiang J K,Zhang Q,et al. Frontiers of Environmental Science\&Engineering . 2016.

10. Ministry of ecology and environment. Gb17691-2018 emission limits and measurement methods for heavy duty diesel vehicles (CHINA VI) [S]. Beijing: China Environment press, 2018

11. Fu Haichao, Experimental study of particle emission characteristics for Direct Injection Gasoline Engine[D]. Beijing: Tsinghua University 2013.

12. FAN Xiaoxiao;JIANG Jingkun, et al.Characteristics of Particles Emitted by a Gasoline Direct Injection Vehicle Under Different Dilution Conditions and Measurement Systems[J]. Proceedings of the CSEE, 2016,36(16):4452-4458+4533. 